\title{
Problems of Sincerity
}

\section{Citation}

Moran, Richard. 2005. Problems of sincerity. Proceedings of the Aristotelian Society 105, no. 1: 325-345.

\section{Published Version}

http://dx.doi.org/10.1111/j.0066-7373.2004.00117.x

\section{Permanent link}

http://nrs.harvard.edu/urn-3:HUL.InstRepos:3160485

\section{Terms of Use}

This article was downloaded from Harvard University's DASH repository, and is made available under the terms and conditions applicable to Other Posted Material, as set forth at http:// nrs.harvard.edu/urn-3:HUL.InstRepos:dash.current.terms-of-use\#LAA

\section{Share Your Story}

The Harvard community has made this article openly available.

Please share how this access benefits you. Submit a story.

Accessibility 
Richard Moran

Meeting of the Aristotelian Society

June 21, 2004

\section{Problems of Sincerity}

The difficulties of intimacy or the unobstructed meeting of minds are so various that it has occurred to more than one writer over the centuries that the fundamental problem here arises from our basic metaphysical condition as embodied human beings. In the Enneades, Plotinus describes the happy condition of souls when they have at last reached the heavenly region and are no longer encumbered by the physical bodies that once housed them, and makes a striking comparison between the soul's emancipation from physical embodiment and it's freedom from the need for words or other signs to make itself known to others.

\footnotetext{
"We certainly cannot think of them [souls free of the body], it seems to me as employing words when, though they may occupy bodies in the heavenly region, they are essentially in the Intellectual [...] [T]here can be no question of commanding or of taking counsel; they will know, each, what is to be communicated from another, by present consciousness. Even in our own case here, eyes often know what is not spoken; and There all is pure, every being is, as it were, an eye, nothing is concealed or sophisticated, there is no need of speech, everything is seen and known."1
}

So we might say: in a better world, there would be no need for speech, for the purpose of speech, and communication generally, can only be to make manifest the contents of one's mind, and there nothing would obstruct the view of one mind to another. A certain familiar picture of the meaning and value of sincerity gains expression in this passage. We value sincerity in speech, and in expression generally, because it is the closest we can come to unmediated access 
to the genuine state of mind of the person we are communicating with. In the context of putatively informative communication, we value speech because it is a reliable and fine-grained guide to the beliefs of the other person, and we value the person's beliefs themselves because they are often an indispensable and reliable guide to the facts in question. The smile, if sincere, takes us to the pleasure of the other person, and the statements he makes, if sincere, take us to his genuine beliefs about some matter we are interested in. And since the other person's words are only of interest to us insofar as they are a reliable guide to his beliefs, we would do just as well, and perhaps better, if we had more immediate access to those beliefs, dispensing with the need for verbal expression and all of its risks and inadequacies. Then we would be in a position to make up our own minds as to the epistemic value of his beliefs as a guide to the facts themselves, and we would be able to do this without the risks incurred by the additional inference from his possibly insincere speech to his beliefs and other states of mind. From the perspective of this ideal, sincerity belongs with the virtues that seek to make themselves unnecessary, but at the cost of treating speech itself as a lamentable expedient for purposes of real communication. The world of unimpeded communion of souls, as described by Plotinus, is for reason of that very purity an utterly silent world. There is nothing to say, simply because in that state of existence everything goes without saying.

This picture is a natural expression of the thought that sincerity matters to speech because its presence is our guarantee that what the speaker says is an accurate representation of what he actually believes. If what we hear from a speaker is to be believable, it is because the speech we hear provides us with access to what the speaker's own beliefs are, and his statements will be believable only to the extent that we are counting on his beliefs on this matter to be reliable. 
Hence since it is access to the beliefs of the other person that is doing all the real work here, it need not matter just how this access is achieved so long as it is understood that, other things being equal, we should prefer access that was free of the mediations of explicit speech and the risks inherent in the assumption of sincerity.

I will be arguing against this picture, both as an understanding of what sincerity is and as an understanding of the importance of sincerity in speech. The epistemic status of another person's beliefs is importantly different from that of the words he speaks, and the importance of his speech is not simply that of an indicator of what his beliefs are. Further, the role of the assumption of sincerity in speech is not that of a guarantee that the speaker's words reflect his actual beliefs, but is in fact something both weaker than that in one way, and stronger in another way.

We can begin with the following natural assumption about the role of sincerity in speech: since assertion aims at belief on the part of the hearer, this aim cannot be achieved unless the hearer assumes that the speaker believes what he says. This provides a straightforward explanation of the norm of sincerity in assertion, and in recent years Timothy Williamson and others have argued that the considerations in favor of this norm in fact support the stronger norm that in assertion the speaker not only believes what he says, but knows it as well. ${ }^{2}$ I will not be directly addressing the 'knowledge requirement' in this paper, except to the extent of arguing that even the belief requirement has a more restricted application than is usually assumed. This is one place of many where I have benefitted from the discussion of assertion and sincerity in Bernard Williams' Truth and Truthfulness (Princeton University Press, 2002), although Williams ties assertion to the expression of belief in ways that I think ends up mischaracterizing the 
specific type of expression of belief for which sincerity matters.

Early in Chapter Four, Williams argues against the assimilation of the sense in which "belief aims at truth" to a norm of truth for assertion, for while falsity is a "fatal objection" to a belief (in that recognition of its falsity on the part of the believer amounts to abandoning it as a belief), there is no comparable fatality with respect to statements that are false. As he says, "We appropriately utter - that is, come out with - false sentences in all sorts of contexts." (70). This is so not only because not all statements present themselves as assertions, but also because not all assertions present themselves as candidates for belief, at least in the sense of being informative to the hearer (71). And yet, when it comes to assertions which do aim to change the beliefs of the audience, Williams suggests that the speaker must at least present himself as believing what he is saying. With respect to the idea that "we cannot typically make sense of someone who seems to be asserting something he does not believe to people who, as he well knows, know that he does not believe it,", he says that "an explanation of it might be this: that an assertion is an utterance intended to bring it about that the hearer believes its content, and this is not an intention which, in these circumstances, the speaker can intelligibly have. This places assertion firmly in the context of one person's telling something to another." (70 - 71) I think it is indeed true that it is only the notion of telling and not the broader notion of assertion that can make sense of the requirement on the speaker's beliefs here, and the general importance of sincerity itself. As mentioned earlier, not all assertion aims at the beliefs of the hearer in the first place, and for these there may be no interest on the part of the hearer in whether what is said reflects the beliefs of the speaker. What Williams suggests above, however, is that when the aim of assertion is belief in the content of what is said, it will be clear to both speaker and audience that this aim 
cannot be achieved unless the speaker is assumed to believe what he says. This may seem obvious enough, especially if we are thinking of the audience asking itself the question "Why should I believe this if he doesn't?", but in fact this question will often enough have a straightforward answer, with the reasons for believing what is said being quite independent of the speaker's own attitude toward it. For assertions are made, with the aim of being convincing, in the context of such activities as formal debate, ad hominem argument, or the following out of a proof, where the convincingness of what is said in these contexts need not depend at all on the assumption that the speaker himself believes what he is saying. In situations of this sort, assertions can function as reminders, challenges, probings or orientations for the mind, and when successful they can be convincing on their own. Assertions are made and directions are given by the speaker helping someone follow a proof, but the aim here is that the reasons themselves will be found convincing, independent of any assumptions about the actual attitudes of the speaker.

In cases like these, the speaker may be aiming to say true things, but he is not himself aiming to be believed. The context is in a natural sense an informative one, but the speaker is playing a different role in the production of belief than he is when he tells someone something. In this way the question of what the speaker himself believes does not have the same relevance for the hearer in the two cases, when he is considering whether to believe what has been said. There will be more to say about the relevance of the speaker's beliefs later, as it pertains to the specific form of informative assertion involved in telling. In particular, I will say more about how the speaker's presentation of his own belief is supposed to play a role in bringing the hearer to believe that very thing. But when the context of assertion is not informative in the first place we might think that conveying beliefs about the speaker's beliefs would only have less of a role 
to play. Williams, however, disagrees and in so doing he argues for a significant asymmetry between sincerity and insincerity.

I have made the point that sincere assertion do not necessarily have the aim of informing the hearer; but insincere assertions do have the aim of misinforming the hearer. In the primary case, they aim to misinform the hearer about the state of things, the truth of what the speaker asserts. Derivatively, they may aim to misinform the hearer merely about the speaker's beliefs: the speaker may know that the hearer will not believe what he falsely asserts, but he wants her to believe that he himself believes it. We should say, then, that the standard conditions of A's asserting that $\mathrm{P}$ are that:

A utters a sentence "S," where "S" means that $P$, in doing which either he expresses his belief that $\mathrm{P}$, or he intends the person addressed to take it that he believes that P. (74)

But the very asymmetry claimed here should give us pause. Why should the general point of an assertion necessarily have anything to do with conveying beliefs (true or false ones) about the speaker's own beliefs? If I open a book and read the sentence "The world is everything that is the case", surely an assertion is being made here, and yet it does not matter to my relation to this statement whether it expresses the actual beliefs of the author, nor does its functioning in my thought depend on my taking it that it does so. Most importantly for our purposes it doesn't matter to the believability of that statement that I take it to reflect the beliefs of the speaker.

And if sincere assertion need not have any sort of informative intent (either about the facts or about the beliefs of the speaker), why cannot insincere assertions also take place in a context where informing or misinforming are simply not the issue? For instance, a teacher is examining a student and asks him to describe the chief causes of the American Civil War, and 
the student dutifully and intelligently outlines the causes as they were presented in lectures, which, let us assume, downplayed the role of slavery in the origins of the conflict. Perhaps the student himself is unconvinced by the line taken in the lectures, but is nonetheless quite good at outlining the approach presented there. So he speaks insincerely, and does not go into his own thoughts on the matter. The context is one where both teacher and student assume that there is no reporting or exchange of information about the Civil War itself, so that is not the aim of the speaker. And in this situation I don't see why it should be the aim of the student to be misinforming the teacher about his beliefs on the matter either. In situations like these the beliefs of the speaker need not enter in as an object of concern at all. The teacher may simply want to know that the student has understood the lectures and can discourse on them competently. And if this is right, and situations like this are common enough, I don't see reason to deny that the student is engaged in making assertions when he says things like "The issue of the scope and authority of the federal government divided North and South for reasons quite independent of the extension of slavery to the new territories". Similarly, assertions are made in the context of formal debate and ad hominem argument where there need be no assumption that one is being informed either about the facts or about the beliefs of the speaker.

What I think this shows so far is that not all assertions aim to be informative or misinformative at all, neither about the facts themselves nor about the beliefs of the speaker. And then within the class of assertions that are informative in the sense of aiming at the beliefs of the audience, some of these achieve their aim through something more like reminding or demonstrating and do not depend for their convincingness on assumptions about the beliefs of the speaker. For these, sincerity need not play any role in achieving the aims of assertion. 
Finally, within the class of assertions whose aim is informative some of these have the aim that the speaker himself be believed, and these have the force or intent of telling the audience something. For these assertions the success of the aim does involve the hearer's assumption that the speaker believes what he says, for he is being invited or instructed to share that very belief.

But just what is the role of this assumption in the case of telling? In particular, if the hearer will not be convinced unless he assumes that what the speaker says reflects what he believes, does that mean that all the hearer is really concerned with is what the speaker's beliefs are, such that if he could arrive at this knowledge without being told anything his epistemic position would be just as good or better? That would take us back to the conception of sincerity I derived from the picture of transparent communication in Plotinus, where the value of sincerity would be that of a fallible guarantee that the speaker's words reflect his actual beliefs. If we know his belief independently of intention to make it manifest, it seems we can dispense with any reliance on the external signs of belief. But a person's beliefs, like his other attitudes, may gain expression in his behavior in various ways, and even his explicit statements can be revealing about much more than the particular belief being asserted. Not every belief that the hearer discerns in these ways will provide him with a reason to share that belief, so if sincerity contributes to the believability of what is said it must do more than provide a glimpse into the mind of the speaker. The speaker himself, and not just the fact of his belief, must play a role in constituting a reason for his audience to believe something. We need to look more closely into just how beliefs gain expression in sincere assertion.

When Williams says that insincere assertions must have the aim of misinforming the hearer, an important intuition guiding him here is that of the naturalness of sincerity over 
insincerity in speech. So, while saying what one genuinely believes about some matter may be the natural, default response to a question about it, and hence need not raise any specific question as to the motives of the speaker for speaking sincerely here, speaking insincerely does seem to require something like a decision on the part of the speaker to deviate from the natural response, and hence does raise the question of the specific motives of the speaker for doing so. In this sense, then, there is a real difference between sincerity and insincerity. Sincere speech does not immediately raise any question as to why the speaker chose on this occasion to express his actual beliefs. Expressing one's actual beliefs through assertion just is the immediate, natural response in speech situations, and as such it functions independently of the intent either to inform or misinform. It is for reasons of this sort that Williams frequently characterizes sincere assertion as the spontaneous or "direct expression" of one's belief. By contrast, expressing something other than one's actual beliefs is something that calls for some explanation, specifically an explanation in terms of the motives of the speaker regarding his audience, and so it seems that these motives could only be deceitful, either with respect to the facts or his beliefs or both at once. Even so, I think examples such as the ones above show that such motives need not be deceitful at all. The person speaking in an examination or a debate may well have specific motives for departing from the spontaneous expression of his actual beliefs, but these motives need not have anything to with misinforming his audience either about his beliefs themselves or about the facts in question. It is indeed significant that the natural, spontaneous response to any question calling for an assertion is to come out with one's actual beliefs, and Williams places illuminating emphasis on this throughout this chapter. ("Sincerity at the most basic level is simply openness, a lack of inhibition." 75) It is also this emphasis on the naturalness of 
truthful expression over untruthful expression that accounts for his linking of sincere assertion with a special sense of directness in the expression of belief. This formulation is first introduced and emphasized on p. 74 , but is returned to throughout the chapter. [78, 79, 80, 81]

"What better expression could there be of that belief than that sentence, and what belief could be better expressed by its utterance? There are, of course, other ways of expressing one's beliefs; we can say that someone who asserts that $\mathrm{P}$ and is sincere says something that is a direct expression of his belief that P." (74)

In this passage, there is a question about directness, and a question about what makes an expression of some belief "better" than some other one. If we restrict expressions to verbal expressions, then it may well go without saying that there is no better verbal expression of the belief that $\mathrm{P}$ than the utterance of "P" itself. But not all our beliefs, let alone other states of mind we report or give expression to, are so closely tied to words for it to be true that there can be no better expression of them than the utterance of some sentence. If we think of 'expression' as covering a wider field than the verbal, and if a "better" expression is one that is more expressively adequate than some other one, then it won't be hard to imagine situations where there is indeed some more adequate expression (e.g., of my belief about the superiority of one performance to another, or about the quality of irritation in someone's voice) than the utterance of a roughly corresponding sentence. Or, alternatively, if what makes one expression better than another is that it is a more reliable guide to the truth about the state of mind in question, so that what is at issue is basic accuracy or reliability rather than expressive adequacy, then there are different reasons for doubting that the assertion of "P" will always be the better expression. For any assertion is an intentional act, and only counts as any kind of indication of the person's state 
of mind insofar as it is presented in a certain spirit, as a sincere assertion and not some other kind of verbal performance, and hence considered as a reliable indication of a person's actual belief, explicit assertion is subject to all the risks involved in relying on a deliberate expression that may be deliberately misleading. And even when the person's sincerity is not in question, his sincere assertion can still only be as accurate or reliable as his self-knowledge. As compared with other ways of reading off someone's beliefs from what he does (whether deliberately or not), relying on what he says involves the audience in further layers of mediation inseparable from the character of saying something as an intentional act. And this in turn raises questions about the idea of assertion as a "direct expression" of belief. ${ }^{3}$

People's beliefs gain expression continually in what they say and do, and not every mode of expression of belief provides the audience with the type of reason for conviction that ordinary testimony does. Beliefs and other attitudes gain expression in the absence of any intent to communicate, simply through our actions and how we perform them, and for this very reason this might be thought of as a more direct form of expression than one involving the complexities of intention involved in telling someone something, however spontaneous truthful assertion may be. This applies to verbal behavior as much as it does to non-verbal behavior. As Williams points out, "All sorts of inferences may be reasonably made from what people say and the ways in which they say it. [...] [H]earers gather more from a speaker's making a particular assertion than the content of that assertion. As I put it earlier, the speaker expresses one belief, but they acquire many. Speakers have countless beliefs and many different ways of expressing them." (99 - 100) Some forms of the expression of belief involve the speaker asserting or explicitly giving his word on something, whereas other forms of expression may manifest beliefs or other 
attitudes which he may not even be aware of, but which are evident to the right sort of audience. In Erving Goffman's formulation, there is the distinction between "the expression that he gives, and the expression that he gives off." ${ }^{4}$ In both cases the hearer may gain access to the beliefs of the speaker, and from this he may indeed learn about the facts themselves that these beliefs represent. But learning by being told something is a different affair from learning by inference from what I pick up about the speaker's beliefs. Corresponding to the difference between what the speaker "gives" and what he "gives off" is the difference between what I learn from him and what I may learn from what he does and how he does it. Only in the case of what I learn from him, the person, does my relation to his beliefs involve the speaker's assuming any responsibility for what I believe, and that makes a difference to the kind of reason for belief that is obtained in the two cases. The role played by the assumption of his sincerity here is thus something more than a guarantee of access to what his beliefs are.

The central difference is between expression in the impersonal sense of the manifestation of some attitude or state of mind, and expression in the personal sense as the intentional act of one person directed to another. To see this, let us leave the case of the expression of belief for a moment and consider the case of an apology or an expression of gratitude. We do want these to be sincere, of course, and to reflect what the person is actually feeling. But it doesn't follow from this that the importance of sincerity in such cases lies entirely in providing a kind of guarantee that the verbal apology or thanks are indications of genuine remorse or gratitude on the part of the speaker. For there are common enough situations where it is as clear as can be that someone is indeed sorry for what happened or grateful for the help, that how they look and act is a more reliable and unequivocal indication of their state of mind than any words could be. Yet 
finding oneself in such a situation does not do away with the need for words. And this is because the words provide something more than an indication of the speaker's state of mind. For one thing, there is the difference between remorse or gratitude expressing itself in a person's face or action, and the person giving expression to his remorse or gratitude. When we need the person as such to get involved in the explicit expression of remorse or gratitude, this is not out of the assumption that this will always provide a more reliable guide to the state of mind we are interested in, more reliable than what may express itself in his face and gesture. In such a situation I may know everything I need to know about how this person is feeling, since this expresses itself in countless ways, in voluntary and involuntary behavior. When the person expresses himself, however, he doesn't simply provide a window on to his state of mind, but also "owns up" to the attitude in question, acknowledges it, and assumes a certain kind of responsibility for it, and for my knowledge of it. None of this is part of the story when his remorse or gratitude simply manifest themselves, clear as day, in how he looks or what he does. Hence we need to attend to the difference between what the person does in expressing himself and what the gratitude or remorse within may do in making itself manifest. And the idea of an assumption of responsibility when the person expresses his remorse or gratitude is part of a further difference, which lies in the fact that only when the person as such is involved can we speak of the expression of remorse or gratitude being directed or addressed to some particular other person. When I can read the gratitude in his face this may still leave me not knowing something, though by hypothesis it is not his gratitude itself which I fail to know. What I don't yet know is whether the person is willing to explicitly acknowledge it and address it to me; not only direct my attention to it, though that is of course important to the difference here, and not 
only make this knowledge 'mutual' between us, but also take up a role in constituting a reason for understanding him as grateful or sorry. Putting all this into words highlights the fact that it is the person as such who is asking to be relied on, his choices rather than the natural generalizations linking states of mind with actions and appearances.

Sincerity is an issue where there is a question of believing the speaker as such, and this requires a notion of expression different from the "direct manifestation" of belief. The case of lying may help to clarify this distinction. In the case of explicit verbal expression of belief considerably more of the speaker's attitudes may be given expression than the simple belief that P itself (e.g., that he found this worth saying, that he is willing to help out, etc.). When the speaker is lying, of course, he expresses a belief that he does not have. At the same time, his action of telling a lie may express other beliefs and attitudes of his, ones which the action of lying, and the way he carries it out, reveals him actually to have. His choice of words or the creative elaboration of his lie may express his confidence in his powers, his contempt for his audience, or various other attitudes. ${ }^{5}$ Hence in his lying assertion that $\mathrm{P}$ he both expresses the belief that $\mathrm{P}$, and also while engaged in this lie various of his genuine attitudes also gain expression. And here we can see that the sense of "expression" cannot be the same in the two contexts, the context in which his attitudes are expressed in his behavior and the context in which he makes the explicit, though deceitful, expression of belief that $\mathrm{P}$. One basic difference is simply that in his assertion that $\mathrm{P}$ he expresses the belief that $\mathrm{P}$, whether or not he actually has any such belief; whereas when we speak of the beliefs and other attitudes which are given expression in someone's behavior, the very description itself implies that we are normally thinking of expression here in a 'factive' sense, such that speaking of some attitude expressing 
itself implies the presence of that very attitude. If I begin by characterizing someone's behavior as expressing his confidence in his powers, and then become convinced that he had no such confidence, then I withdraw the original claim that this is what his behavior expressed. His behavior at the time seemed to express his confidence, but I now see this is wrong. By contrast, were the person himself to have explicitly announced such confidence to someone, the claim that this is what he expressed survives any later revelation that in fact he felt no such thing. The main difference here is between expression as a quite general term for the various ways in which phenomena are made manifest, and "express" as verb of intentional action, something done by a person. Hence we can refer to a 'personal' and an 'impersonal' sense of expression. A person's fear or belief may express itself in various ways that the person himself may not control or even be aware of. But the person himself can only express his fear or his belief if he is aware of it and means to make it manifest. Or rather, he can do this on the assumption that he has the fear or the belief in question. A person who makes a lying profession of belief that $\mathrm{P}$ is still said to have expressed the belief that $\mathrm{P}$, in that this is what he intended to convey. But here too, the insincere person will only be said to have expressed the belief that $\mathrm{P}$ insofar as he was aware that it was this belief he was seeking to convey. Thus in the case of either the sincere or insincere expression, the person as such is said to have expressed the belief that $\mathrm{P}$ only insofar as he was aware of this belief, either as his actual belief or as the belief he was seeking to convey.

The fact that speaking is itself a form of expressive behavior sometimes causes confusion on this point. The distinction I am drawing between the personal and the impersonal senses of 'expression' is sometimes assimilated to the distinction between linguistic and non-linguistic expression, with the assumption that linguistic expression is personal expression, in being the 
conscious act of a person to make manifest a particular attitude. But since they are actions, speech and assertion will always involve consequences beyond the conscious control of the person, and hence will always have the potential to be revealing of the person beyond what he intends to convey. Hence the example of lying shows not only the difference between the two dimensions of expression, but shows how both types of expression have application within the domain of speech and assertion itself. The liar expresses one belief with his assertion that $\mathrm{P}$, while another belief (one that he actually has) gains expression through the act of lying itself. ${ }^{6}$

The central question for the role of sincerity in assertion is the one Williams raises in Chapter Five: "What is the relation between the speaker's beliefs and the beliefs with which the hearer ends up?" (96). What the foregoing discussion shows, I believe, is that there are two possible relations here, two ways in which learning of the speaker's beliefs can come to be a reason for my believing the same thing. I may come to know what his beliefs are from all that he says and does, and treat the fact of his belief as on a par with other evidence I may possess. Or I can learn what someone believes from what he tells me, and here the epistemic import of the words he speaks is different from that of his belief itself. From the hearer's perspective, the speaker's words are a reason to believe something only insofar as they are presented by him in a certain spirit (e.g. as an assertion or something else), whereas his beliefs about some matter may be good evidence for the facts themselves, in a way that has nothing to do with them being presented in a certain spirit, or indeed on them being presented at all. If the importance of sincerity were restricted to guaranteeing access to the speaker's beliefs, then in making the other person aware of his beliefs the speaker would have done his job as far as informing him is concerned. But if this were all that is involved in telling someone something then the liar or the 
verbal misleader really would be able to say that he cannot be blamed because all he did was provide evidence for what his beliefs are and leave his audience to draw their own conclusions from this. (Williams, pp. 107, 118) But telling someone something is much more directive than this, pointing the audience in a verbally specific direction, attesting to the truth of what is being said, and not just anything and everything that might be garnered from the person's speech and action. (The 'directive' aspect of telling someone something shows up in the fact that the verb 'to tell' has various imperative forms that are not shared by 'to say' or even 'to assert'. I may not only tell someone the facts, but I may also tell him to back off, or tell him how to get back on the highway.) This directive aspect of telling is only possible insofar as the person as such is involved in the act of expression. For the invitation to trust that it presents to the audience is predicated on the speaker presenting himself as assuming responsibility for his speech being a reason to believe something in the first place (as they would not be, for instance, if those same words are presented as some other speech-act). This is not a relationship he stands in with respect to his beliefs or with respect to any other evidence, and in these ways the speaker is doing something quite other than allowing his beliefs to be known and leaving the audience to draw their own conclusions. A person leaves his audience to draw their own conclusions when the epistemic import of the phenomenon from which they draw their conclusions does not depend on him.

These considerations cast doubt on the idea that the value of words, the value of sincere words, can only be that of a reliable indication of the person's beliefs. The intentional act of the person in giving explicit expression to his belief and addressing this assertion to someone else provides his hearer with something more than he could have derived from the simple awareness 
of the speaker's beliefs themselves. In telling someone something he does not simply lay his belief open to view (which can happen even with respect to an unconscious belief of his), something for the hearer to make of what he will, but rather registers his consciousness not only of the belief itself but of the fact that he is engaged in providing his hearer with a reason to believe that very thing. The 'directive' aspect of telling, attesting to a specific proposition, is thus related to the speaker's presentation of himself as accountable for the hearer's believing what he says. Simply gaining awareness of what someone believes provides nothing of this relationship between speaker and hearer.

However, the role of the person as such in providing a reason to believe also means that in an important sense the hearer gets something less from sincere assertion than he would from direct access to the speaker's beliefs (and these two facts about the personal level of expression are related to each other, and illuminate the nature of sincerity itself). And this is because although sincere expression involves no intent to deceive, it also need not be terribly discerning about the self to which it gives expression. As Williams says, "It follows from the basic spontaneity of assertion that Sincerity does not typically involve a special exercise of Accuracy, namely, Accuracy in discovering what it is that I believe; rather, in the simplest case I am confronted with my belief as what I would spontaneously assert. There are, of course, other cases in which I do have to discover by inquiry what I believe." (76) Not only does sincerity not require any special exercise of accuracy, but it is a familiar fact about sincerity that it is compatible with error or simple shallowness about one's own attitudes, including one's beliefs. Matthew Arnold speaks of the "surface stream [...] of what we think we feel", and its stark contrast with the noiseless current below of "what we feel indeed", and he is clear that it is from 
this surface perspective that sincere expression takes place. ${ }^{7}$ A person is credited with speaking sincerely when he presents himself as he takes himself to be, which may not involve reporting his own beliefs accurately. In this way the demands of sincerity are weaker than the demands of accurate presentation of one's beliefs or other attitudes. If someone fails to know his actual belief about some matter, whether through self-deception or more innocently, he will still be speaking sincerely when he asserts the belief he takes himself to have. But in another sense, the requirement of sincerity is more demanding than the accurate presentation of one's state of mind. For again, if someone has the repressed belief, for example, that he is a coward, but takes himself to believe no such thing, he will have failed to speak sincerely if, for his own reasons he nonetheless says that he is a coward, even though by hypothesis what he asserts here expresses what he actually thinks about himself. As D. H. Mellor and others have pointed out, a person speaks sincerely when he says what he takes himself to believe, and not simply when he says what he in fact believes. Just as it is possible to lie while inadvertently reporting the actual facts, it is possible to speak insincerely while asserting what is in fact one's actual belief. ${ }^{8}$ Saying what I actually believe is not sufficient for sincerity, if the belief expressed is not what I take myself to believe. And saying what I actually believe is not necessary for sincerity either, since I still speak sincerely if I am somehow wrong about my actual belief but nonetheless assert what I take myself to believe.

In these ways, sincerity fails to be a guarantee of access to the speaker's actual beliefs, and hence from the point of view of the picture of sincerity that we began with, all this should make it quite mysterious why sincerity should have any central importance at all to the epistemology of testimony. What it suggests is that we cannot make sense of the importance of 
sincerity for testimony unless we separate this from the assumption that the importance of sincere assertion is that of providing access to the speaker's beliefs. As we saw, the believability of some assertions doesn't rely on assumptions about the speaker's beliefs in the first place, and what the current considerations aim to bring out is that with respect to the class of assertions where the beliefs of the speaker are crucial, whereby the speaker tells his audience something, sincerity does not function as a guarantee of access to the speakers beliefs, but provides something both stronger and weaker than that. Sincere assertion is a weaker guarantee than that, since it only provides us with the speaker's own apprehension of himself, which may be limited in various ways. But this same fact leads to an understanding of how sincere assertion provides the hearer with an kind of epistemic relation to the facts that he could not get merely through knowing what the speaker believes.

We gain access to another person's beliefs and other attitudes through what they say and do, and the expression of belief takes various forms, conscious and unconscious, voluntary and involuntary. Only with respect to what I have called "personal expression", the intentional action of expressing one's belief, is the person in a position to speak for the meaning or epistemic import of what he is attesting to. With respect to whatever else may express itself in someone's speech or other expressive behavior, while this may indeed be a source of knowledge for the audience, they are on their own as far as assessing its epistemic significance goes. Since beliefs which are revealed in these ways need not even be known by the speaker himself, the hearer (or observer) cannot assume that the speaker is in a position to offer support or justification for what may be garnered in this way, nor that he speaks with any authority about the meaning or general significance of the belief which manifests itself in his speech or other 
behavior. Ultimately the speaker's relation to what expresses itself in his behavior is no different from his relation to what his act of lying may reveal about him. And indeed, this is true for beliefs which someone may learn of in ways that have no basis in overt expression at all. In such a situation, the audience cannot look to the person as such to say anything helpful about the belief's meaning, its justification, or how it would alter in response to counter-evidence of various kinds. By contrast, in the ordinary speech exchanges associated with testimony, it is taken for granted that if someone asserts that $\mathrm{P}$, the hearer is not on his own in the task of assessing its meaning or its epistemic significance. In making the assertion, the speaker has taken on the burden of responding to a request for clarification, interpretation or justification.

In these ways, the kind of reason for belief presented in assertion is different from the kind of reason for belief that may emerge from what expresses itself in speech. And it is with respect to the sort of reason presented in assertion that sincerity takes on a special importance, even while we acknowledge that sincerity does not even insure that it is the speaker's actual beliefs that are being expressed. The speaker is sincere when he asserts what he takes himself to believe. If people were typically mistaken in this, then perhaps sincerity would be worthless as condition on the acceptability of testimony. But if people really were typically mistaken about their own beliefs, then it is doubtful that we would have the practice of telling and offering testimony. As things are, on the assumption that people are generally right about their own beliefs, sincerity offers the hearer something that could not be gained by knowing the speaker's beliefs more directly. With that assumption in place, the speaker's telling me what he takes himself to believe about $\mathrm{P}$ will provide me not only with knowledge of his actual beliefs, but will bring me into contact with the person as such and his capacity for offering justifications as well 
as interpretation of the general significance of the belief. And it does this because fulfillment of the sincerity condition presents me with what he takes himself to believe, and not simply with his belief itself. In this way I am not left on my own in the task of interpreting it and assessing its epistemic significance, but instead the speaker acknowledges his role to play in the belief's interpretation and justification. Thus sincerity matters to the joint responsibility of the testimony-based knowledge. It is this joint responsibility, and the role of sincerity in establishing it, that underpins the fact that in testimony the speaker gives his assurance for this very proposition, the very one he is asserting, and not anything or everything that might be garnered from his act of assertion.

If something I say or do provides evidence for some fact, it is irrelevant to this evidential force whether or not I know that what I said or did provides such a reason for belief. Nor, in such a case, do I need to know how it constitutes such a reason for belief. But when a person makes a committed assertion, he must recognize the sort of reason he is offering, and his role in constituting it as a reason for belief. Hence sincerity matters to testimony because it is from this position that the speaker assumes responsibility for the meaning and justification of what he says. This is a genuine epistemological difference for the hearer, providing something different from what he would get simply from access to the other person's beliefs. And in this way the linguistic nature of testimony is related to the role of consciousness in presenting someone with a reason for belief. It is only from a position of consciousness of what he is doing that a speaker can make a promise or give his word on something. The speaker is authoritative with respect to, and hence assumes responsibility for, what illocution his words present, whether as a promise, a prediction, or an hypothesis. To count as a mature speaker of a language is to be credited with 
investing one's words with the force of, say, an assertion rather than a question or a recitation. And from the hearer's point of view, he will not have any idea of the epistemic import of what he has heard until he knows which illocution the speaker is presenting himself as enacting. Hence for the hearer to know what to make of this utterance, whether as evidence or anything else, he must assume that the speaker is speaking from within the authority to constitute his utterance as, say, an assertion rather than a recitation. If the person is not assumed to speak for himself here, then the hearer cannot take himself to be receiving any kind of testimony from him at all, whatever epistemic stance the hearer may ultimately want to adopt toward it.

We do want and expect what people tell us to be both true and to express their actual beliefs, and often enough we are not disappointed in these expectations. But the importance of sincerity is not simply that of learning the speaker's beliefs, because that would suggest that any way we might come to know these beliefs would have the same epistemic import as the speaker's assertion. And that would fail to account for the person's own role in constituting his utterance as a reason to believe something, his addressing his assertion to another person, and his attestation to a specific candidate proposition; none of which is part of the person's relation to his expressive behavior or his beliefs themselves. In addition, the understanding of the role of sincerity in terms of access to the speaker's beliefs leaves unexplained the importance of the limited way in which sincerity does relate to such access, since it is neither necessary nor sufficient that sincere speech reflect the actual beliefs of the speaker. One can fail to speak sincerely while nonetheless giving expression to one's actual beliefs, just as one can speak sincerely in a way that reflects a very imperfect grasp of one's actual attitudes. Sincerity matters epistemically to the hearer not because it provides him with a window onto the speaker's beliefs 
but because it tells him what the person as such is assuming responsibility for, as this relates to the hearer's own belief. The difference doesn't simply lie in the fact that he now has someone to blame should he turn out to be misled, but also in the more epistemically relevant fact that, rather than having simply come upon someone's belief to make of what he will, the hearer can assume that the belief in question has survived the speaker's reflection on it and is being presented to him with the speaker's epistemic backing and answerability for its justification and general (including contextual) significance. As with any assumption of responsibility, this can be something shallow, confused, or deluded, but the speaker's explicit presentation of what he says as belief-worthy, and the joint responsibility for belief expressed by this, nonetheless provides the hearer with something of an epistemic import different from the private or telepathic discovery of someone's beliefs. ${ }^{9}$

\author{
Richard Moran \\ Department of Philosophy \\ Harvard University
}


1. Plotinus, Enneades. Trans. Stephen Mackenna (London, 1956), IV. 3, 18.

2. Williamson, Knowledge and its Limits (Oxford University Press, 2000).

3. As to "what belief could be better expressed by its utterance", there may be straightforward answers here too, according to which the belief expressed is not that of the truth of the proposition stated. In a given context, the belief being given expression by its utterance need not be belief in that proposition at all, but rather the belief that, for the present purposes of argument or demonstration or instruction, this is what my audience needs to hear. [...]

4. "Many crucial facts lie beyond the time and place of interaction or lie concealed within it. For example, the "true" or "real" attitudes, beliefs, and emotions of the individual can be ascertained only indirectly, through his avowals or through what appears to be involuntary expressive behavior. [...] The expressiveness of the individual (and therefore his capacity to give impressions) appears to involve two radically different kinds of sign activity: the expression that he gives, and the expression that he gives off." Erving Goffman, The Presentation of Self in Everyday Life (Doubleday, 1959), p. 2.

5. "Man lügt wohl mit dem Munde, aber mit dem Maule, das man dabei macht, sagt man doch noch die Wahrheit.", Nietzsche, Beyond Good and Evil, § 166.

6. If someone can express some belief or some fear without having it, then the relation between the expression and the facts about my genuine attitudes cannot be a purely causal one, but opens up the possibility for such failings as error or misrepresentation. In short, there is a normative as well as a causal relation between expression in the personal sense and what is putatively being given expression. The applicability of such terms of criticism as error or misrepresentation for the personal sense of expression is only appropriate given that here the expression in question is the intentional action of a person, and persons and actions provide just the right sort of object for such criticism.

7. "Below the surface-stream, shallow and light, Of what we say we feel - below the stream, As light, of what we think we feel - there flows With noiseless current strong, obscure and deep, The central stream of what we feel indeed."

Quoted in Lionel Trilling, Sincerity and Authenticity, (Harvard University Press, 1971), p. 6.

8. Mellor uses the term 'assent' for second-order belief, believing that one believes, and says "Sincere assertion is saying what one assents to, that is what one believes one believes, not just what one believes." p.97, in 'Conscious Belief', Proceedings of the Aristotelian Society (1977-8), pp.87-101. The account Mellor gives of assent in that paper has been superceded by the richer account he gives in 'Consciousness and Degrees of Belief', in Prospects for 
Pragmatism: Essays in Memory of F. P. Ramsey, edited by D. H. Mellor (Cambridge University Press, 1991).

9. I am grateful to Adam Leite and Lucy O'Brien for conversations relating to this paper. I have also benefitted from audiences at the Aristotelian Society and at the University of Minnesota. 